\title{
Analysis of Surface Properties of Ag and Ti Ion-Treated Medical Textiles by Metal Vapor Vacuum Arc Ion Implantation
}

\author{
Ali Akpek ${ }^{1,2}$ (D) \\ 1 Department of Bioengineering, Faculty of Engineering, Gebze Technical University, 41400 Kocaeli, Turkey; \\ aliakpek@gtu.edu.tr \\ 2 Sabanci University Nanotechnology Research and Application Center, Sabanci University, \\ 34956 Istanbul, Turkey
}

check for updates

Citation: Akpek, A. Analysis of Surface Properties of $\mathrm{Ag}$ and $\mathrm{Ti}$ Ion-Treated Medical Textiles by Metal Vapor Vacuum Arc Ion Implantation. Coatings 2021, 11, 102. https://doi. org/10.3390/coatings11010102

Received: 30 November 2020

Accepted: 12 January 2021

Published: 18 January 2021

Publisher's Note: MDPI stays neutral with regard to jurisdictional claims in published maps and institutional affiliations.

Copyright: (C) 2021 by the author. Licensee MDPI, Basel, Switzerland. This article is an open access article distributed under the terms and conditions of the Creative Commons Attribution (CC BY) license (https:// creativecommons.org/licenses/by/ $4.0 /)$.

\begin{abstract}
The study focuses on the effects of Ag (silver) and Ti (titanium) ions on textiles by MEVVA (metal vapor vacuum arc) ion implantation. In order to comprehend this, the research was executed in three parts. In the first part, the antibacterial efficiencies of $\mathrm{Ag}$ and $\mathrm{TiO}_{2}$ were investigated in detail since the antibacterial capabilities of $\mathrm{Ag}$ and $\mathrm{TiO}_{2}$ are well known. A group of polyester- and cotton-based medical textiles were modified by $\mathrm{Ag}$ and $\mathrm{TiO}_{2}$ ions, with doses ranging from $5 \times 10^{15}$ to $5 \times 10^{16} \mathrm{ion} / \mathrm{cm}^{2}$. To determine the adhesion capabilities of the implanted ions on surfaces, after the first round of antibacterial tests, these medical textiles were washed 30 times, and then antibacterial tests were performed for the second time. The results were also compared with nanoparticle-treated medical textiles. In the second part, the corrosion and friction capabilities of Ag and Ti ion-implanted polyester textiles, with a dose of $5 \times 10^{15}$ ion $/ \mathrm{cm}^{2}$, were investigated. Finally, the UV protection capabilities of $\mathrm{Ag}$ and $\mathrm{Ti}$ ion-implanted polyester textiles, with a dose of $5 \times 10^{15} \mathrm{ion} / \mathrm{cm}^{2}$, were investigated. The experiments showed that even after 30 washes, the $\mathrm{TiO}_{2}$ ion-implanted polyester textile had almost $85 \%$ antibacterial efficiency. In addition, Ti ion implantation reduced the friction coefficiency of a polyester textile by almost $50 \%$ when compared with an untreated textile. Finally, the Ag-ion-implanted polyester textile provided a UV protection factor of 30, which is classified as very good protection.
\end{abstract}

Keywords: surface engineering; ion implantation; MEVVA; antibacterial; corrosion; UV protection

\section{Introduction}

As nanotechnology becomes a part of our daily lifestyle, nanotextile products have become one of the most important gains of this new progress. Each and every day, international corporations offer new nanotextile products to the market, and, every day, these products get a bigger market share. Stain-resistant, liquid-repellent, odor-resistant, antimosquito, and antistress textiles have already been made available everywhere in the world. Nowadays, one of the most important topics in the nanotextile area is antibacterial research [1,2].

International corporations and scientists have been working for almost 30 years on antibacterial textiles and developing new products [3,4]. However, none of these products' antibacterial ability has been successful, cheap, unlimited or briefly useful enough for customers. Due to this reason, only a small percentage of the world population use antibacterial technologies for their clothes.

On the other hand, resistant pathogens have created a major problem for health services. As an example, Staphylococcus aureus can develop resistance to methicillin and, because of this, each and every year, millions of people die from this deathly hospital infection. To reduce the death rate of this infection, hospital clothes and wound dressings that include silver particles were developed. It is very well known that silver ions and silver-based compounds are highly toxic to microorganisms [5]. However, even these novel products are not satisfactory enough. 
There have been several attempts to create antibacterial textiles. Li et al. reported the potential use of alginate for antibacterial textile production [6]. In a similar approach, Turakhia et al. developed copper oxide nanoparticles on cotton fabrics [7], Zemjic et al. developed chitosan nanoparticles [8], Fouda et al. developed zinc oxide nanoparticles [9], and Ouadil et al. prepared Ag-loaded graphene nanocomposites for antibacterial medical textile development [10]. All these studies have claimed to have $100 \%$ antibacterial ability at the end of the research. However, since nanoparticles are not immune to laundering, their antibacterial ability after several washouts is still unknown.

For all these reasons, new methodologies have been investigated to make nanotextiles cheaper and more successful. In addition to that, it is very important for these improved textiles to preserve their antibacterial efficiencies even after several rounds oflaundering. Previous studies have never provided this information. It is also obvious that one particular surface modification technique is one step ahead of all other techniques. This technique is called ion beam implantation technology.

There are three methods commonly used for ion implantation. These methods are mass-analyzed ion implantation (MAII), direct ion implantation (DII), and plasma source ion implantation (PSII). One of the most recent ion implantation techniques is metal vapor vacuum arc (MEVVA), a type of DII ion source implantation. The method used in this study is MEVVA ion beam implantation technology.

Ion implantation is a green, environmental-friendly surface engineering technology. During ion implantation, processed heat on the surface of the material is between 40 and $100{ }^{\circ} \mathrm{C}$. Therefore, no corruption of any material can be observed between this heat range. The main principle of ion beam implantation technology relies on accelerating and bombarding ions to the surface of the targeted material under vacuum and providing them improved surface properties. Collided ions do not affect the bulk structure of the main material. The main mechanical properties of the modified materials are protected. The MEVVA source incorporates a cathode, where cathode materials and ion species can quickly be generated and put into the ion extractor. The source also includes a powerful magnetic field and injection of gas into the ion extractor. Then, the desired ion beams can be generated. The voltage of the ion source extraction can be a maximum of $100 \mathrm{kV}$. The ion beam is a broad beam of $10 \mathrm{~cm}$ after the extraction. The radial beam redirects with magnets and evolves into a broader beam until the ion acceleration column. Finally, the accelerated ions arrive at the end station and are implanted into the surface material. This entire process is explained in Figure 1.

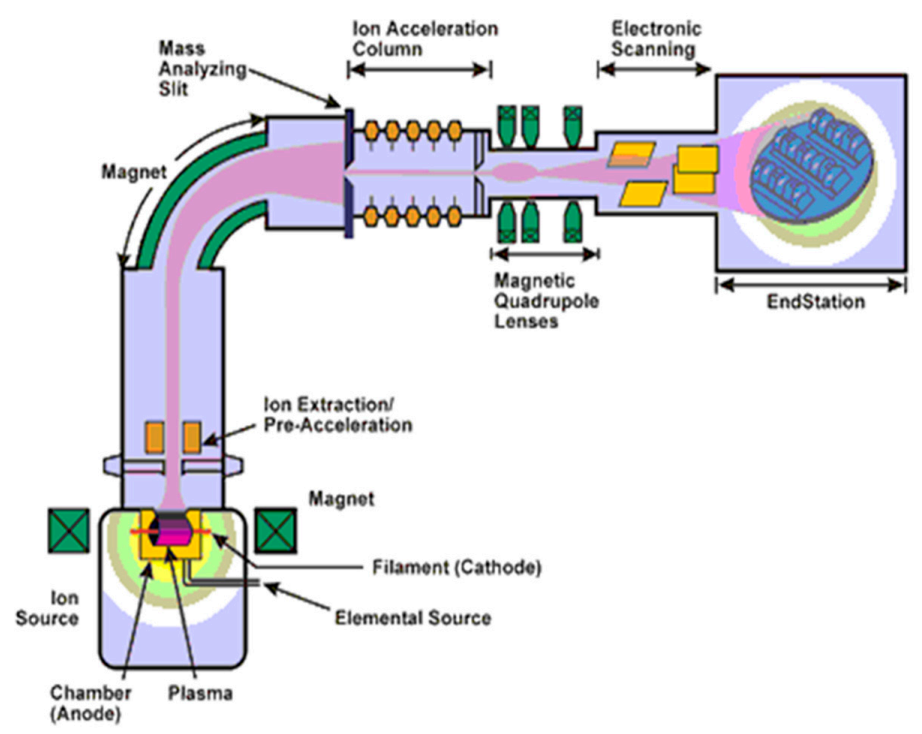

(a)

Figure 1. Cont. 


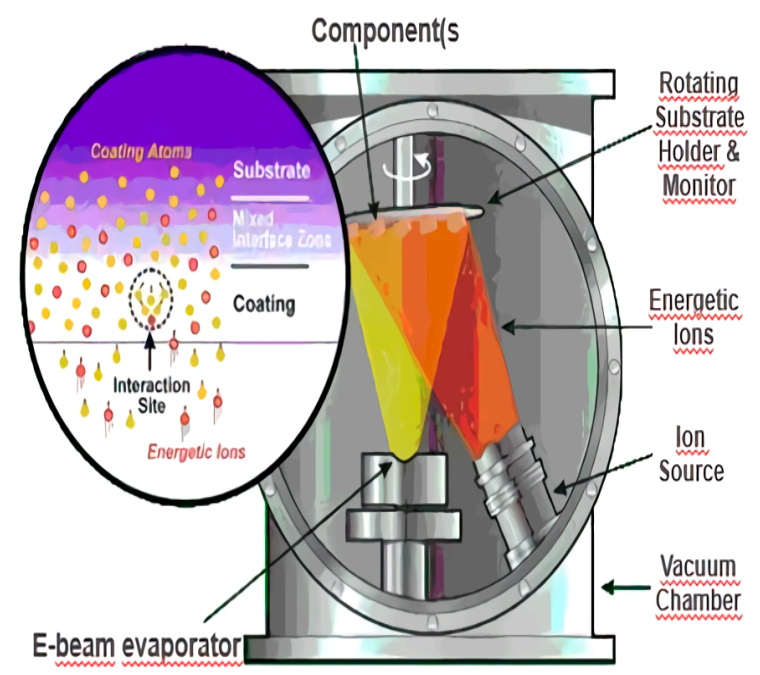

(b)

Figure 1. (a) The creation and acceleration of ion beams. (b) Ion implantation inside surface materials [11,12].

Ion implantation is a surface modification technique that enables us to modify surfaces with such desired abilities as corrosion resistance, friction resistance, biocompatibility, hydrophilia, hydrophobia, and antibacterial efficiency. These are only some of the abilities that ion implantation technology can provide metal, ceramic, plastic, and polymer material surfaces [13]. Unfortunately, there are only a few studies where MEVVA has been used for textiles [13-15]. The only study where MEVVA was used for creating antibacterial ability was achieved by us with very limited resources. That research pioneered our current research. As an addition to our previous studies, in this research, the antibacterial effects of $\mathrm{Ag}$ and $\mathrm{TiO}_{2}$ are investigated more precisely, SEM analysis is achieved, UPF factor and friction resistance capabilities are also analyzed, and all data are categorized as evidence of the general effects of $\mathrm{Ag}$ and $\mathrm{TiO}_{2}$, especially on medical textiles. Therefore, this research may have a serious impact on the future development of smart textiles that are specifically for medical purposes.

$\mathrm{Ag}$ (silver) and $\mathrm{TiO}_{2}$ (titanium dioxide) are known for their antibacterial abilities [16,17]. Due to these reasons, these ions were selected for implantation. Friction and UV protection capabilities were also analyzed to figure out the other advantages or disadvantages of Agand Ti-implanted polyester fabrics. There is enough evidence in the literature to claim that these ions may contribute seriously to the friction and UV protection capabilities of materials $[18,19]$. Therefore, these tests were also conducted on ion-implanted polyester textiles.

This study is one of the first studies to use MEVVA ion beam implantation technology as an alternative nanotextile technology. To evaluate its potential commercial value, the results were compared with the antibacterial efficiency results of commonly used and commercially available nanoparticles. Additionally, in order to determine the adhesion capabilities of the implanted ions and nanoparticles treated on the surfaces, after the first antibacterial tests, these medical textiles were washed 30 times, and antibacterial tests were performed a second time. The results were compared afterward.

\section{Experiments}

\subsection{Ion-Implanted Fabrics}

The cotton- and polyester-based medical textiles (Labor Textile Inc., Izmir, Turkey) were cut into a $10 \times 10 \mathrm{~cm}^{2}$ size, with $0.1 \mathrm{gr} / \mathrm{cm}^{2}$, and sent to the MEVVA ion beam implantation laboratory. In this article, cotton fabric refers to $100 \%$ alpaca cotton fabric and polyester fabric refers to $75 \%$ polyester fabric with $25 \%$ cotton. These textiles were selected 
since they are the most commonly used medical textiles in the market [20]. The textiles were fabricated for medical use in the first place.

A vacuum arc ion source (MEVVA) based metal ion implantation system was used on the fabrics to enhance their surface properties. An MEVVA system is shown in Figure 2. This MEVVA source utilizes the principle of vacuum arc discharge between the cathode and the anode to create dense plasma from which an intense beam of metal ions of the cathode material is extracted. This metal ion source is operated in pulse mode. In our MEVVA system, when Ag was used, the ion source was adjusted to pulse with $50 \mathrm{~Hz}$ frequency for $250 \mu$ s time duration $(\zeta)$ and an ion beam current of $2 \mathrm{~mA} / \mathrm{cm}^{2}$. The device worked under $4 \times 10^{-6}$ Torr pressure. When $\mathrm{Ti}$ or $\mathrm{TiO}_{2}$ was used to obtain antibacterial ability, the ion

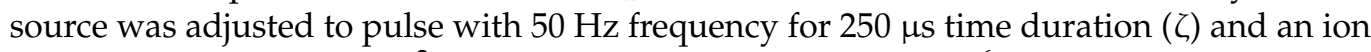
beam current of $1 \mathrm{~mA} / \mathrm{cm}^{2}$. The device worked under $5 \times 10^{-6}$ Torr pressure. Titanium ions and oxygen ions were accelerated and implanted individually, and, for each of them, previous values were used in this study. When oxygen ions are implanted after titanium ions, they spontaneously merge with each other and form $\mathrm{TiO}_{2}$ (titanium dioxide).

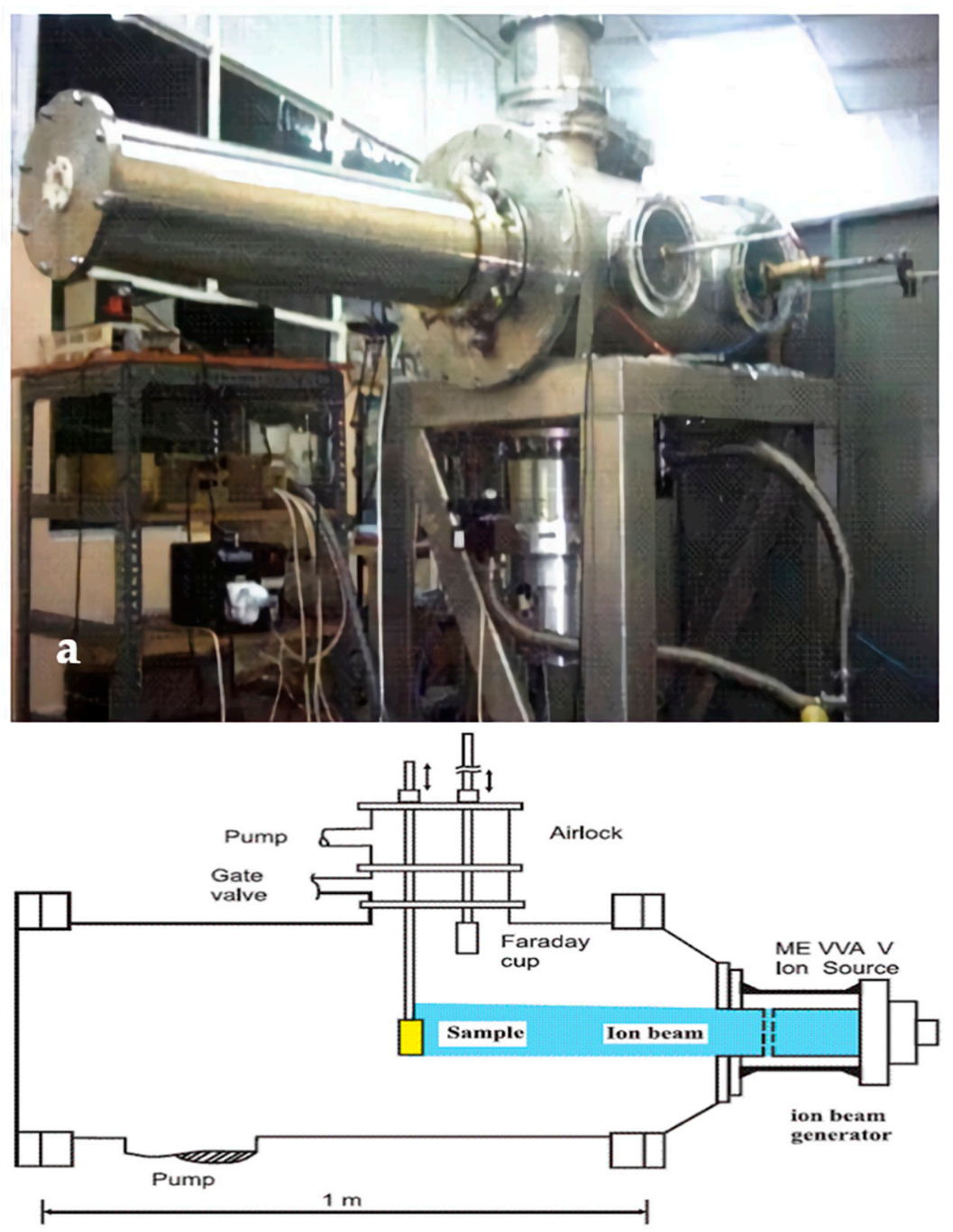

(b)

Figure 2. (a) MEVVA (metal vapor vacuum arc) ion implantation system. (b) Schematic illustration; Reprinted with permission from [14]; Copyright 2008 Elsevier.

In this research, the determination of the upper limits of the ion implantation dose and the pulse repetition rate was a serious challenge. These values were determined as a compromise between the ion dose levels and the goal of creating significantly improved surface 
features. In this research, we explain the results obtained for implantation doses between 5 $\times 10^{15}$ and $5 \times 10^{16} \mathrm{ion} / \mathrm{cm}^{2}$. Further increases in the ion dose caused surface overheating, and, therefore, they were not used. These doses were determined experimentally. In normal conditions, lower ion doses can only provide minor surface changes; however, in this study, ion doses between $5 \times 10^{15}$ and $5 \times 10^{16} \mathrm{ion} / \mathrm{cm}^{2}$ were still satisfactory enough to create surface modification and, hence, characterization.

The ion source extraction voltage can be increased up to $110 \mathrm{kV}$. The substrate was placed in a vacuum chamber and bombarded by a beam of highly energized ions. $\mathrm{Ag}$ and $\mathrm{Ti}+\mathrm{O}$ were implanted at an accelerating voltage of $30 \mathrm{kV}$ using a MEVVA ion implantation source, with doses ranging from $5 \times 10^{15}$ to $5 \times 10^{16}$ ions per $\mathrm{cm}^{2}$.

The ion penetration depth depends on both the energy of the ions and the atom density in the substrate. The effective parameters of MEVVA are ion species, energy, and ion dose and ion flux [21].

The features of the ion-implanted fabrics are shown in Table 1.

Table 1. Features of ion-implanted medical textiles.

\begin{tabular}{cccc}
\hline No. & Antibacterial Agent (Cathode) & Fabric Type & Ion $/ \mathbf{c m}^{\mathbf{2}}$ (Dose) \\
\hline $\mathrm{I} 1$ & $\mathrm{Ag}$ & Cotton & $5 \times 10^{15}$ \\
$\mathrm{I} 2$ & $\mathrm{Ag}$ & Cotton & $5 \times 10^{16}$ \\
$\mathrm{I} 3$ & $\mathrm{Ag}$ & Polyester & $5 \times 10^{16}$ \\
$\mathrm{I} 4$ & $\mathrm{Ag}$ & Polyester & $5 \times 10^{15}$ \\
$\mathrm{I} 5$ & $\mathrm{TiO}_{2}$ & Cotton & $5 \times 10^{16}$ \\
$\mathrm{I} 6$ & $\mathrm{TiO}_{2}$ & Cotton & $5 \times 10^{15}$ \\
$\mathrm{I} 7$ & $\mathrm{TiO}_{2}$ & Polyester & $5 \times 10^{16}$ \\
$\mathrm{I} 8$ & $\mathrm{TiO}_{2}$ & Polyester & $5 \times 10^{15}$ \\
\hline
\end{tabular}

\subsection{Nanoparticle-Treated Samples}

There are many techniques in nanotechnology that provide antibacterial ability to textile surfaces [22]. However, only one technique was used in this study to provide antibacterial ability to the textile surfaces: the fixation of nanoparticles. This technique is also the most common method of providing desired abilities to textiles.

Table 2 presents the features of nanoparticle treated medical textiles.

Table 2. Features of nanoparticle-treated medical textiles.

\begin{tabular}{ccc}
\hline Sample No. & Antibacterial Agent & Sample Type \\
\hline $\mathrm{N} 1$ & $\mathrm{Ag}$ & Cotton \\
$\mathrm{N} 2$ & $\mathrm{TiO}_{2}$ & Polyester \\
$\mathrm{N} 3$ & $\mathrm{TiO}_{2}$ & Cotton \\
$\mathrm{N} 4$ & $\mathrm{Ag}$ & Cotton \\
$\mathrm{N} 5$ & $\mathrm{Ag}$ & Polyester \\
\hline
\end{tabular}

The fixation of nanoparticles on the textile surfaces was achieved as follows: First, isopropanol was added to the ammonia aqueous solution of $\mathrm{AgNO}_{3}$. Secondly, the $10 \times 10 \mathrm{~cm}^{2}$ piece of cotton or polyester textile was immersed in this solution and boiled for $1 \mathrm{~h}$. Finally, the cotton or polyester sample was removed from the solution, washed with water, and sonicated several times before drying at $25^{\circ} \mathrm{C}$. At the end of this procedure, $\mathrm{Ag}$ nanoparticles were loaded onto the desired cotton or polyester textile. This procedure led to loadings of around $0.1 \mathrm{wt} . \% \mathrm{Ag} /$ cotton, as determined by elemental analysis [23]. The procedure led us to assume the same wt.\% for $\mathrm{Ag} /$ polyester.

The $\mathrm{TiO}_{2}$-loaded polyester/cotton was prepared by immersing the textile sample in a $5 \mathrm{~g} / \mathrm{L}$ suspension of $\mathrm{TiO}_{2}$ Degussa P-25, previously sonicated for $30 \mathrm{~min}$ in bidistilled water. The textile was then dried for $1 \mathrm{~h}$ and sonicated for $5 \mathrm{~min}$ at $75^{\circ} \mathrm{C}$ to eliminate 
loosely bound particles. The loading of the cotton was around $0.1 \mathrm{wt} . \% \mathrm{TiO}_{2} /$ cotton, as determined by elemental analysis [21].

\subsection{Antibacterial Test Procedure}

The antibacterial activities of ion-implanted and nanoparticle-treated samples were evaluated by AATCC Test Method 100-1999 [24] (Assessment of Antibacterial Finishes on Textile Materials). Staphylococcus aureus ATCC 6538 (a Gram-positive organism) was used as a test bacteria for antibacterial activity assessment. All bacterial experiments were implemented using nutrient broth/agar (NB/NA) medium consisting of peptone $5 \mathrm{~g}$, beef extract $3 \mathrm{~g}$, and distilled water $1 \mathrm{~L}$. Fresh transplants of test bacteria were prepared from the stock culture before each experiment.

All swatch samples were cut into rectangles of $3 \pm 0.1 \mathrm{~cm}$ size, and three pieces of fabrics were used for each repetition. All swatches were sterilized in an autoclave $\left(121^{\circ} \mathrm{C}\right.$ $15 \mathrm{~min}$ ) and were placed in sterile petri dishes aseptically. Fresh bacterial suspension was prepared using sterile saline solution $(0.87 \% \mathrm{NaCl}$ in distilled water) according to the McFarland standard $\left(1-2 \times 10^{5} \mathrm{cfu} / \mathrm{mL}\right)$. All samples were inoculated with $400 \mathrm{~mL}$ of bacterial suspension, and petri dishes were closed with parafilm to prevent evaporation during the incubation at $37^{\circ} \mathrm{C}$ for $24 \mathrm{~h}$. After incubation, the swatches were transferred aseptically to a jar containing $40 \mathrm{~mL}$ sterile saline solution as a neutralizing solution and were shaken vigorously for one minute. One series of untreated swatches was used for contact time detection. Serial dilutions $\left(10^{-1}, 10^{-2}\right)$ were made with saline solution and were plated $(100 \mathrm{~mL})$ on nutrient agar plates in duplicate. All plates were incubated at $37^{\circ} \mathrm{C}$ for $24 \mathrm{~h}$. Bacterial colonies were counted, and percentage reduction by the treated specimen was calculated by the following equation:

$$
R=100 \times[(B-A) / B]
$$

$R=(\%)$ antibacterial efficiency reduction.

$B=$ bacterial colonies belonging to untreated swatches, counted from petri dishes just after the inoculation.

$A=$ bacterial colonies belonging to treated swatches (ion-implanted or nanoparticletreated), counted from petri dishes $24 \mathrm{~h}$ after the inoculation.

\subsection{Laundry Procedure}

Eight ion-implanted, five nanoparticle-treated, and two untreated fabrics were weighed as $58.004 \mathrm{~g} \approx 58 \mathrm{~g}$. According to the AATCC 124-2006 [25] Smoothness Appearance of Fabrics after Repeated Home Laundering test methodology, which states that $50 \mathrm{~g}$ of detergent must be used for $1 \mathrm{~kg}$ of fabric, it was necessary for us to use $3 \mathrm{~g}$ of detergent for the $58 \mathrm{~g}$ fabric in the experiment. However, to test the limit of antibacterial ability of the fabrics, $5 \mathrm{~g}$ of detergent was used for the $58 \mathrm{~g}$ fabric.

The fabrics were washed with $50{ }^{\circ} \mathrm{C}$ heated water. Washing progress was realized in a shaking incubator; $3 \mathrm{~L}$ of water was used for the $58.004 \mathrm{~g}$ fabric, according to AATCC 124-2006 test methodology. Fabrics were washed for 30 min with $290 \mathrm{rpm}$ (rotation per minute). After that, the washed fabrics were rinsed in $35^{\circ} \mathrm{C}$ heated water and, finally, they were dried at $40{ }^{\circ} \mathrm{C}$ heat for 25 min inside an incubator.

This test was repeated 30 times. After washing the textiles 30 times, the second round of antibacterial tests was administered to these textiles. Finally, after the second set of antibacterial test results was obtained, it was compared with the first round of antibacterial test results—which were done before the 30 washes - to evaluate which technique is more effective after 30 rounds of laundering.

\subsection{Friction Resistance Test}

The purpose of this test is to determine the appearance of textiles after induced abrasion. The measurements of the corrosion coefficient of textiles are very complex. Friction resistance is affected by many factors, such as inherent mechanical properties, 
dimensions, structures, construction, type, the kind of fabric, and amount of finishing materials added to the fabrics. In order to determine the friction resistance of fabrics, test samples are tested with an abrasive oscillatory cylinder under standard atmospheric conditions and predetermined loads $(50 \mathrm{~N})$ for a prescribed period $(60 \mathrm{~s})$ of time at room temperature. The frequency of oscillation was $0.1 \mathrm{~Hz}$, with a Z-stroke length of $5 \mathrm{~mm}$. These tests were realized according to the ASTM D4157-13 [26] standard test method for abrasion resistance of textiles. Untreated polyester textiles, with the features explained in Section 2.1, were utilized during the experiments [27].

\subsection{UV Protection Factor Test}

UV protection factor (UPF) tests are used to determine the ultraviolet radiation blocked by textiles intended to be used for UV protection [28]. A UPF value can simply be thought of as a time factor for a white-skinned person with skin protection compared to exposure without any protection. As an example, in the case where a person presents visible erythema after three minutes of exposure, fabric with a UPF of 30 extends that time to three minutes multiplied by the protection factor, i.e., $90 \mathrm{~min}$, or, roughly, one and a half hours. The standard tests for computing UPF note that all measurements should be obtained from a UV-visible spectrophotometer that is equipped with an integrating sphere accessory. Fabric samples were placed at the transmittance port of the integrating sphere under moderate tension. Spectra of the fabric samples were collected from 280-400 nm using a special software (Shimadzu UV-vis-NIR spectroscopy, Kyoto, Japan). The software automates the determination of UPF, average UVA transmittance, and average UVB transmittance according to the AATCC 183:2014 [29] standard test method for transmittance or blocking of erythemally weighted ultraviolet radiation through fabrics. Untreated polyester textiles, with the same features explained in Section 2.1, were utilized during the experiments [30,31].

\subsection{SEM Analysis}

Scanning electron microscopy (Philips XL-305 FEG-SEM, Amsterdam, The Netherlands) was used to examine the surfaces of unimplanted and nanoparticle-treated textile surfaces. $\times 45$ and $\times 100$ magnification ratios were used for unimplanted cotton and polyester textiles, respectively. The $\times 3000$ magnification ratio was used to evaluate the effects of nanoparticles on medical textiles. The details of the SEM analysis are written at the bottom of the SEM images.

\section{Results and Discussion}

In Figure 3, the results of all the antibacterial tests, before and after 30 washes, are presented in a graph.

It can easily be analyzed from this figure that the best results gained after 30 washes were the nanoparticle-treated cotton fabric and the ion-implanted polyester fabric.

\subsection{Antibacterial Efficiency Results of Cotton Fabrics}

The reason for this relies on the fact that cotton is a very absorbent fabric and nanoparticles were applied to the surfaces via liquid solutions containing nanoparticles [32]. When liquid solutions containing nanoparticles are applied to cotton fabric, the cotton fabric absorbs a lot of the liquid solution and gains many nanoparticles. As the solvent evaporates away, the nanoparticles start to accumulate on the surface and attach themselves to the surface with the help of physical bonds. This attachment increases as the roughness of the surface increases [33]. This phenomenon also increases the capability of cotton fabric to accumulate more nanoparticles since its roughness is much higher than polyester, as presented in the SEM pictures. 


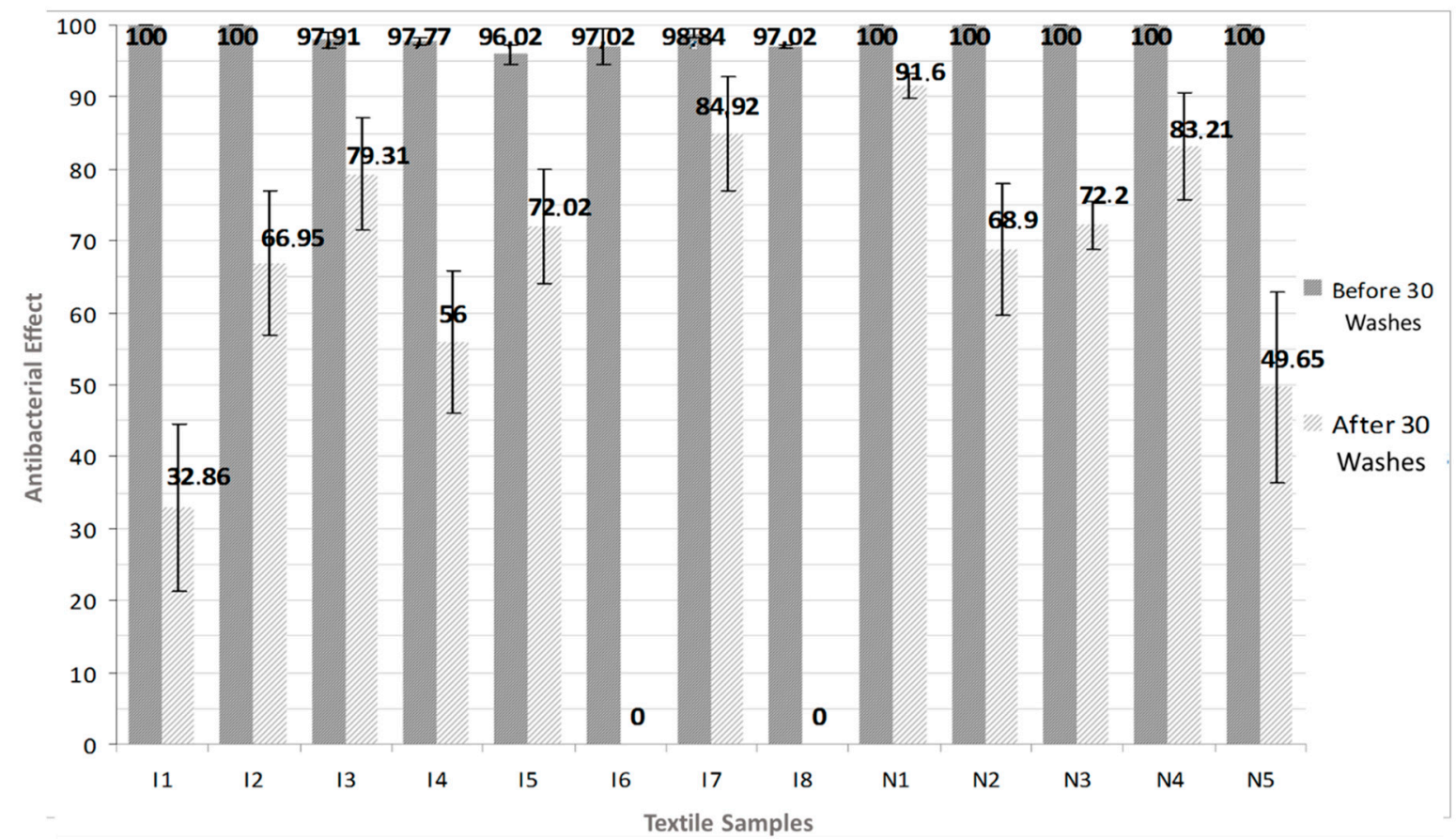

Figure 3. Antibacterial efficiency results, both before and after 30 washes.

On the other hand, polyester fabric is not absorbent as cotton fabric. The roughness of the surface of polyester fabric is also less than cotton fabric. Therefore, it cannot gain as many nanoparticles as cotton fabric can. Due to this reason, after 30 washes, nanoparticletreated cotton fabrics have higher antibacterial efficiency results than both nanoparticletreated polyester fabrics and ion-implanted cotton fabrics since they gained many more nanoparticles at the beginning.

As can easily be understood from the SEM micrograph in Figure 4a, because of surface morphology and the protruding ability of its surface, cotton fabric can hold a high number of nanoparticles, thus causing higher antibacterial efficiency.

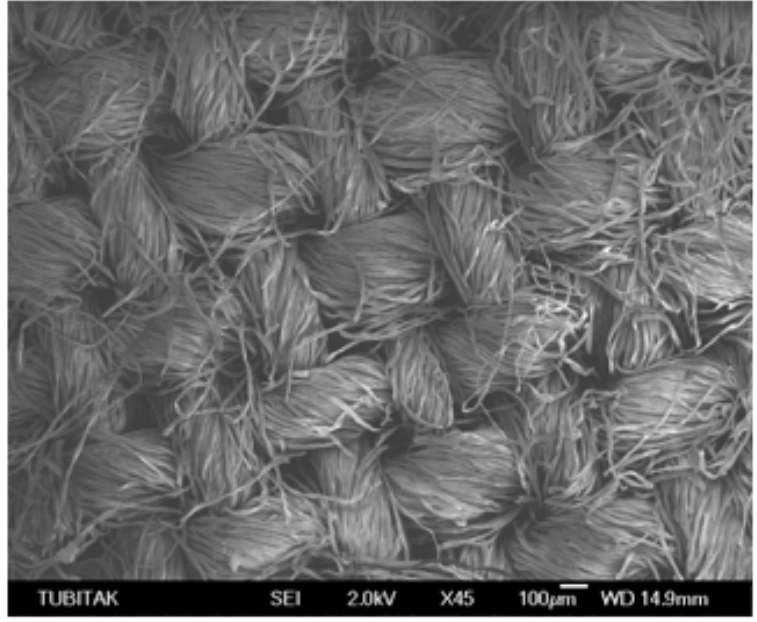

(a)

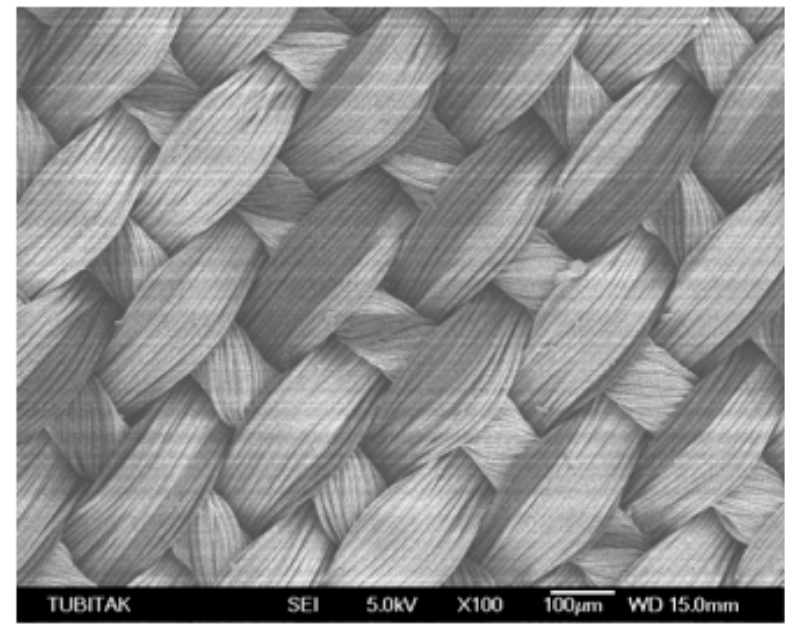

(b)

Figure 4. SEM micrographs of (a) cotton fabric and (b) polyester fabric.

In Figure 5, it can easily be analyzed that nanotextile-based cotton fabrics-N1, N4, and N3-resulted in the highest antibacterial efficiency rates, both after 30 washes and 
even before 30 washes. This is caused by surface morphology and the protruding ability of cotton fabric.

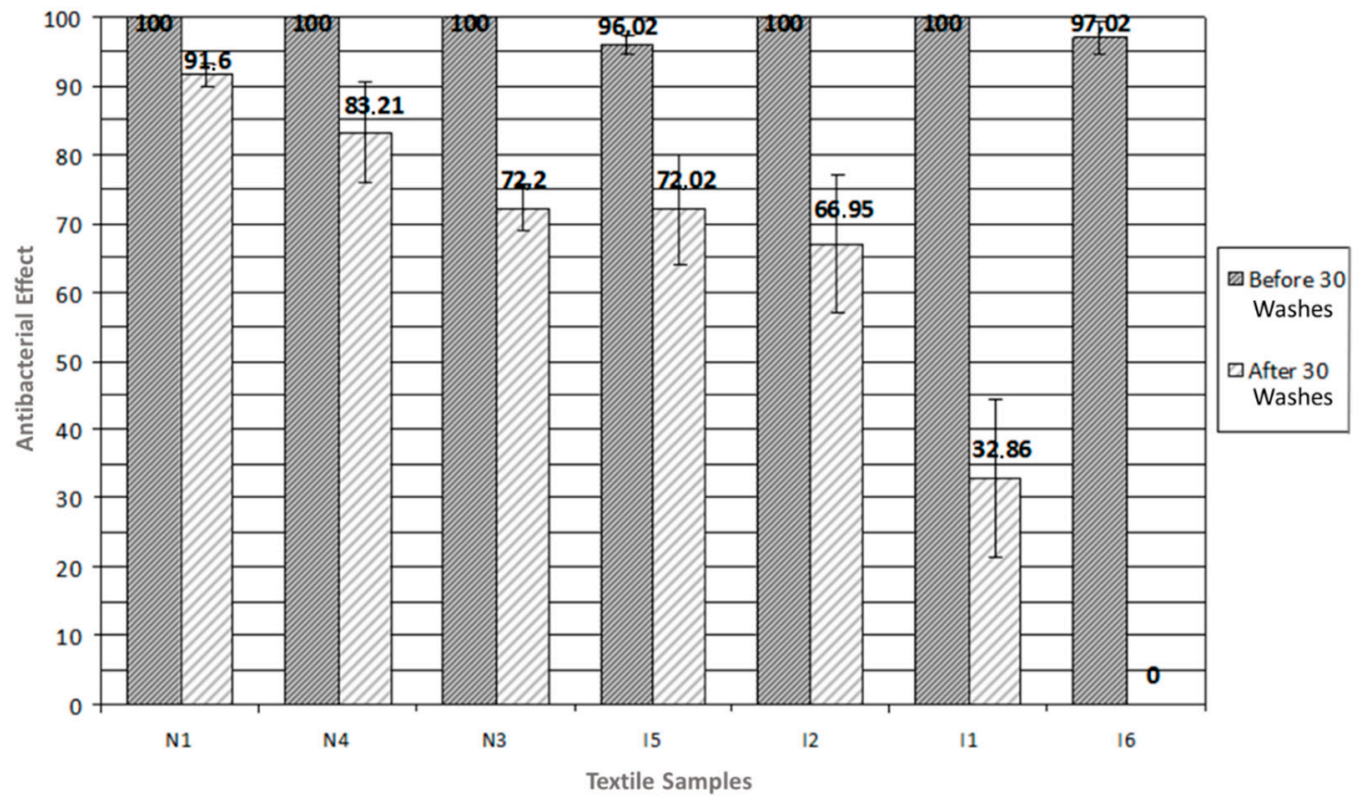

Figure 5. Cotton-based medical textile results gained from both nanoparticle-treated and ionimplanted fabrics.

Figure 6 presents the fibers of nanoparticle-treated medical textiles. As mentioned before, as the solvent evaporates, the nanoparticles accumulate on the surface and attach themselves to the surface and also to each other with the help of physical bonds. On the other hand, for ion implantation, depending on the material, the type of implanting element, and their kinetic energy, the depth of the ion implantation is usually between $0.1-2 \mu \mathrm{m}$. However, the specifications caused by the modification can be observed even at a depth of 50-100 $\mu \mathrm{m}$. Therefore, the breathability and flexibility features of the textile materials do not change since the effect of surface modification is only limited to the surface and does not affect the bulk of the material.

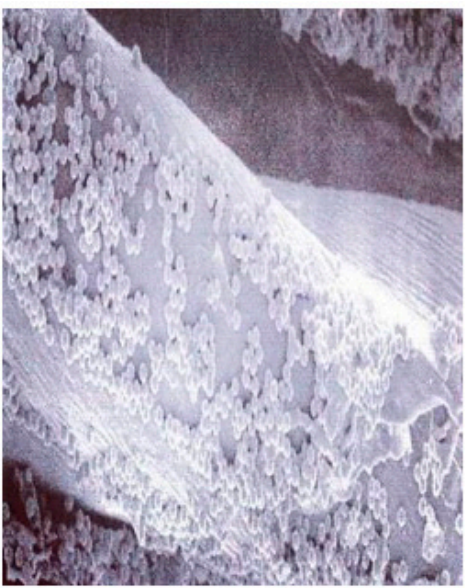

(a)

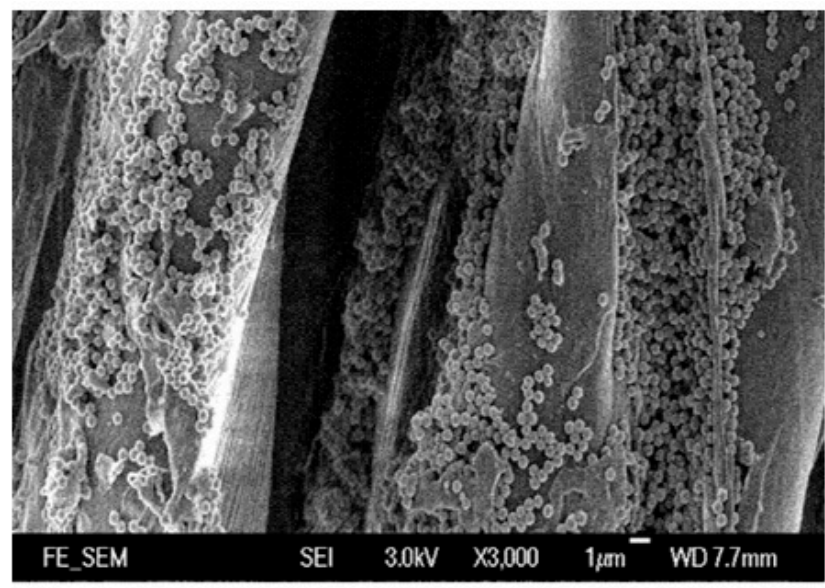

(b)

Figure 6. (a) The fibers of Ag-nanoparticle-treated medical textiles. (b) The fibers of $\mathrm{TiO}_{2^{-}}$ nanoparticle-treated medical textiles.

Figure 7 presents the Staphylococcus aureus colonies in the petri dishes. Each white dot represents a bacteria colony. It can easily be understood that as the antibacterial efficiencies 
decrease, the number of bacteria colonies increases. Before 30 washes, all improved fabrics presented almost $100 \%$ antibacterial efficiencies.
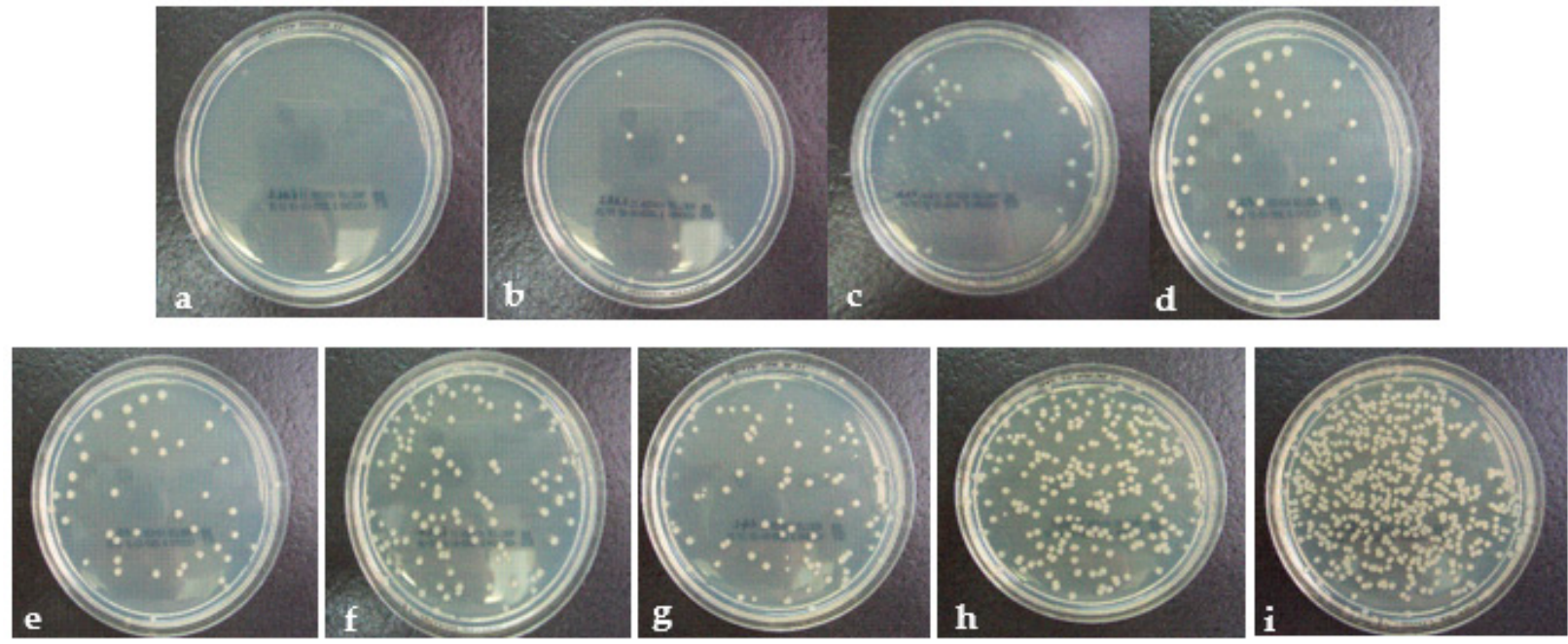

Figure 7. Antibacterial efficiency results before 30 washes: (a) 100\%, (b) 96\%, after 30 washes, (c) N1—91.60\%, (d) N4$83.21 \%$, (e) N3-72.20\%, (f) I5-72.20\%, (g) I2-66.95\%, (h) I1-32.86\%, and (i) I6-0\%.

\subsection{Results of Polyester Fabrics}

It can easily be analyzed from Figure 8 that ion-implanted polyester textiles (especially I7 and I3) are superior to nanoparticle-treated polyester textiles. I7 and I3 also have some of the best results of the experiment.

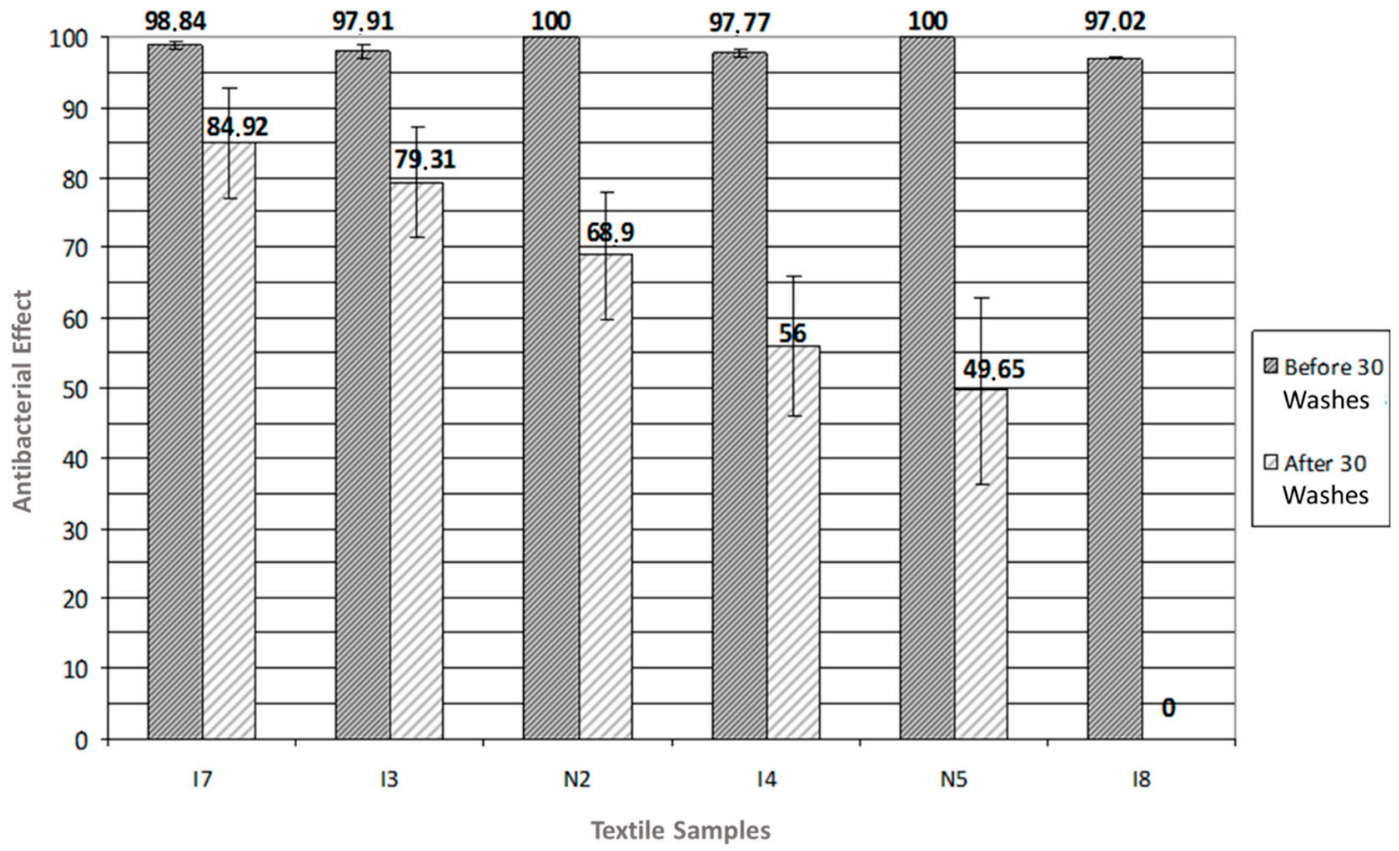

Figure 8. Polyester-based medical textile results gained from both nanoparticle-treated and ion-implanted polyesters. The polyester used in this project was composed of $75 \%$ polyester and $25 \%$ cotton fiber.

Similar to Figure 7, Figure 9 presents the Staphylococcus aureus colonies in the petri dishes. It can easily be understood that as the antibacterial efficiencies decrease, the number of bacteria colonies increases. 

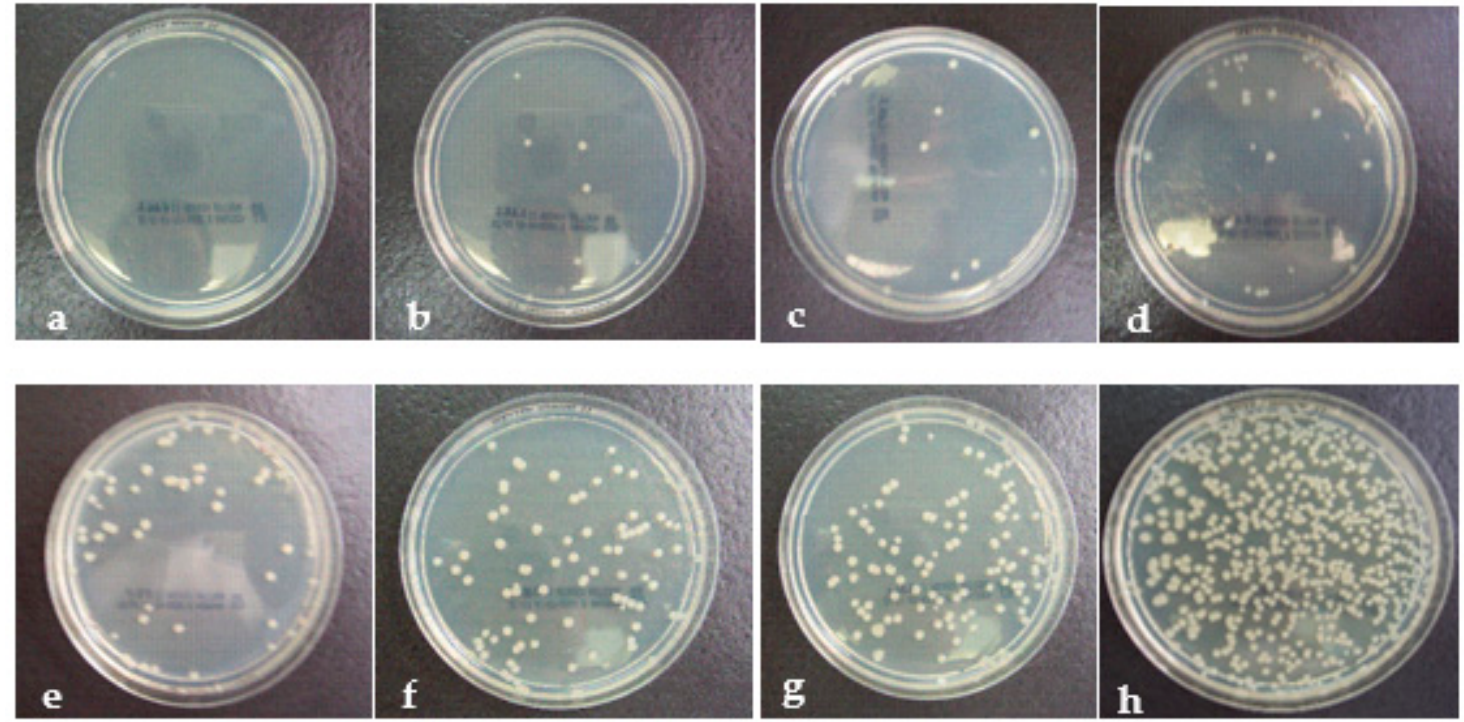

Figure 9. Antibacterial efficiency results before 30 washes: (a) 100\%, (b) 96\%, after 30 washes, (c) I7—84.92\%, (d) I3-79.31\%, (e) N2-68.90\%, (f) I4-56\%, (g) N5-49.65\%, and (h) I8- $0 \%$.

The reason for antibacterial efficiency is that polyester fabrics are densely weaved textiles, and the surface area is much tighter than cotton fabric. As can be understood from the SEM micrograph in Figure 4b, polyester fabric has a smoother and denser weave than cotton. In this study, this had vital importance because smooth areas are better for ion beam implantation and result in higher antibacterial efficiency. Ion implantation technology is surface modification technology, and smoother areas at the textile surfaces are more suitable targets for ion beams. In this case, the ion beams collide with the surface at an inclined angle, and some of the ions are reflected or sputtered from the surface. This may affect the success of ion beam implantation. Therefore, it can be said that if the roughness increases, the success rate of ion implantation decreases. This problem is presented in Figure 10. Based on this fact, even after 30 washes, ion-implanted polyester fabrics have more antibacterial efficiency results than both nanoparticle-treated polyester fabrics and ion-implanted cotton fabrics since they gained many more ion beams at the beginning due to their smooth surface structure.

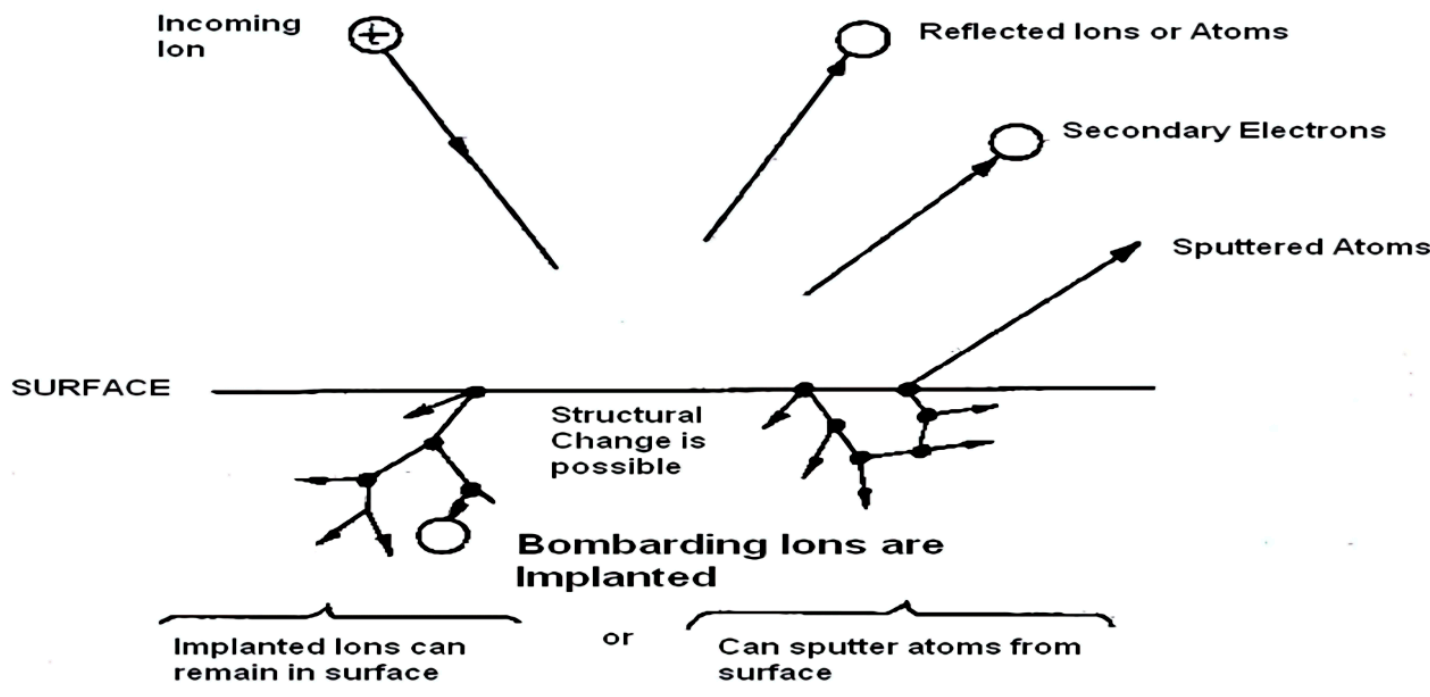

Figure 10. Ion implantation at an inclined angle. 


\subsection{In the Case of Higher Ion Doses}

Table 3 describes the ion $/ \mathrm{cm}^{2}$ based arrangement of features of ion implanted medical textles.

Table 3. Ion $/ \mathrm{cm}^{2}$-based arrangement of features of ion-implanted medical textiles.

\begin{tabular}{|c|c|c|c|}
\hline No. & Ion $/ \mathrm{cm}^{2}$ (Dose) (Cathode) & Fabric Type & Antibacterial Agent \\
\hline I1 & $5 \times 10^{15}$ & Cotton & $\mathrm{Ag}$ \\
\hline I4 & $5 \times 10^{15}$ & Polyester & $\mathrm{Ag}$ \\
\hline I6 & $5 \times 10^{15}$ & Cotton & $\mathrm{TiO}_{2}$ \\
\hline I8 & $5 \times 10^{15}$ & Polyester & $\mathrm{TiO}_{2}$ \\
\hline I5 & $5 \times 10^{16}$ & Cotton & $\mathrm{TiO}_{2}$ \\
\hline I3 & $5 \times 10^{16}$ & Polyester & $\mathrm{Ag}$ \\
\hline I7 & $5 \times 10^{16}$ & Polyester & $\mathrm{TiO}_{2}$ \\
\hline I2 & $5 \times 10^{16}$ & Cotton & $\mathrm{Ag}$ \\
\hline
\end{tabular}

The ion doses used in the project were between $5 \times 10^{15}$ and $5 \times 10^{16} \mathrm{dose} / \mathrm{cm}^{2}$. According to the antibacterial efficiency results, when ion doses were increased, antibacterial efficiency results also increased significantly. If higher doses were used in the research, antibacterial efficiency results would have been much higher before and, especially, after 30 washes. However, a dose rate of over $1 \times 10^{17} \mathrm{dose} / \mathrm{cm}^{2}$ cannot be applied to the fabrics due to overheating.

Figure 11 presents a comparison of similar ion treatments. It can easily be analyzed that when the ion dose increased ten times, antibacterial efficiency results increased over $30 \%$. It is not unrealistic to estimate that if a two-time higher ion dose $\left(1 \times 10^{17} \mathrm{ion} / \mathrm{cm}^{2}\right)$ was used, it would have resulted in much better antibacterial efficiency scores. A logarithmic line is also inserted into the figure in order to make it easier to evaluate the trend caused by the increase in ion implantation dosage.

In addition, Figure 11c, d also present that $\mathrm{TiO}_{2}$ is not as resistive as $\mathrm{Ag}$ against washing. No antibacterial ability was present in $5 \times 10^{15} \mathrm{ion} / \mathrm{cm}^{2} \mathrm{TiO}_{2}$ ion-implanted cotton and polyester textiles after 30 washes. The reason is probably that the laundry process breaks the bonds between titanium and oxygen thus removing the antibacterial ability of $\mathrm{TiO}_{2}$.

\subsection{Friction Coefficiency Results of $5 \times 10^{15} \mathrm{Ion} / \mathrm{cm}^{2}$ Titanium Ion-Implanted Polyester Fabric}

Beyond antibacterial ability, friction and UV protection capabilities were also analyzed in order to understand the other contributions of ion implantation into textile surfaces. Figure 12 shows the pictures of untreated and Ti-implanted polyester textiles. The marks on the surfaces are caused by the friction resistance test, explained in Section 2.5. Due to implantation, the color of the polyester turned from yellow to brown.

As a result, the friction coefficient decreased by $50 \%$ of its untreated first value when $5 \times 10^{15} \mathrm{ion} / \mathrm{cm}^{2} \mathrm{Ti}$ was implanted into the polyester surfaces. Figure 13 presents the friction coefficient results of both textiles. This result implies that the implanted textiles may resist wear and corrosion much longer than untreated textiles; therefore, they may be used for decades longer than untreated ones.

Figure 14 provides much deeper information for this phenomenon. SEM micrographs of untreated and $5 \times 10^{15} \mathrm{ion} / \mathrm{cm}^{2}$ Ti-implanted samples were obtained and compared. It is obviously understood that ion implantation flattens the peaks, fills the trenches, and leads to smoother surfaces. Therefore, due to the nature of ion implantation, ion-implanted surfaces develop friction resistance automatically. 


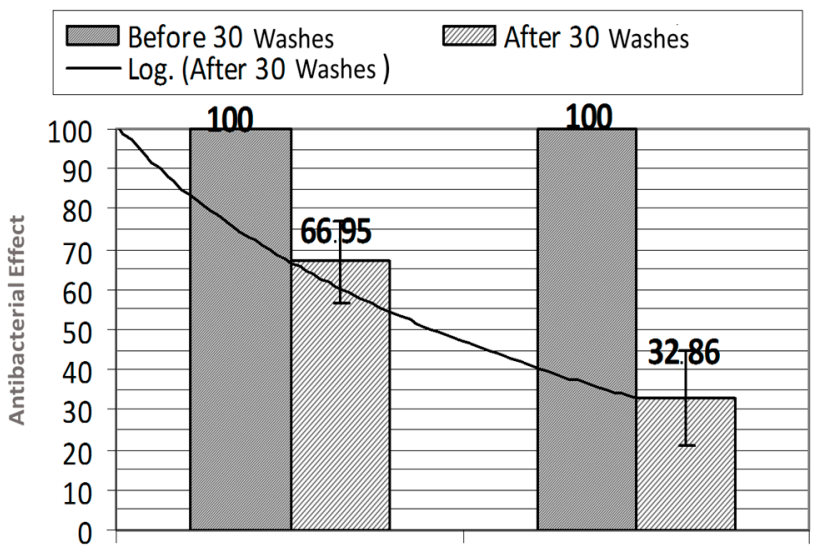

a)

12

Textile Samples

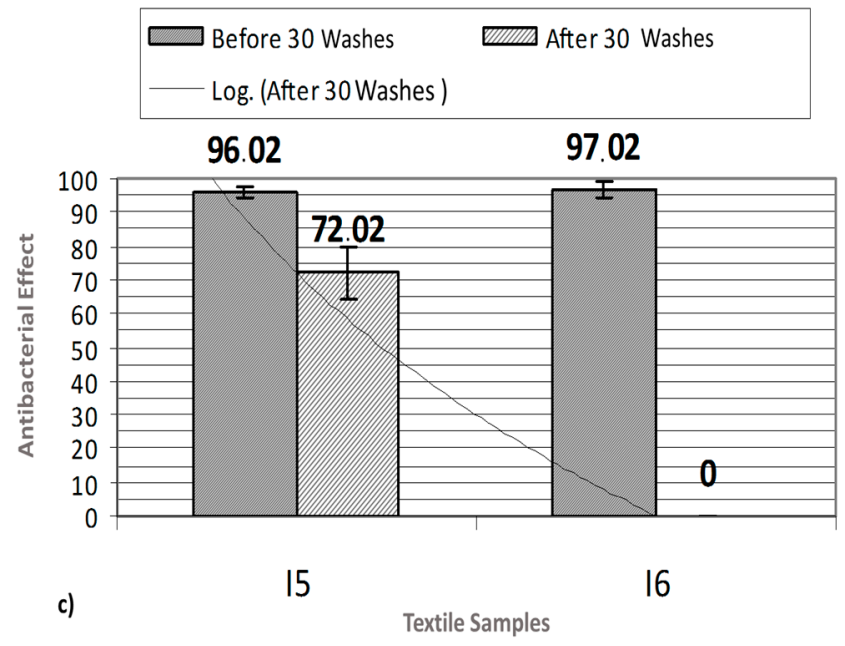

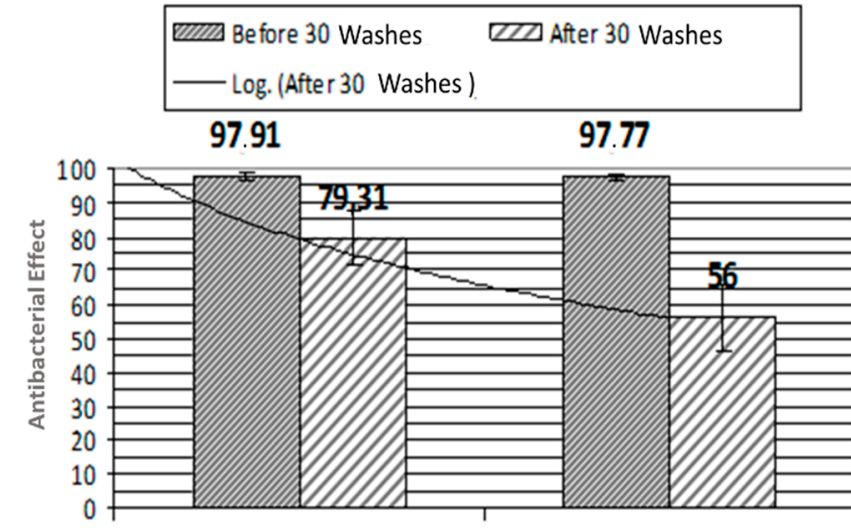

b)

13

Textile Samples

14

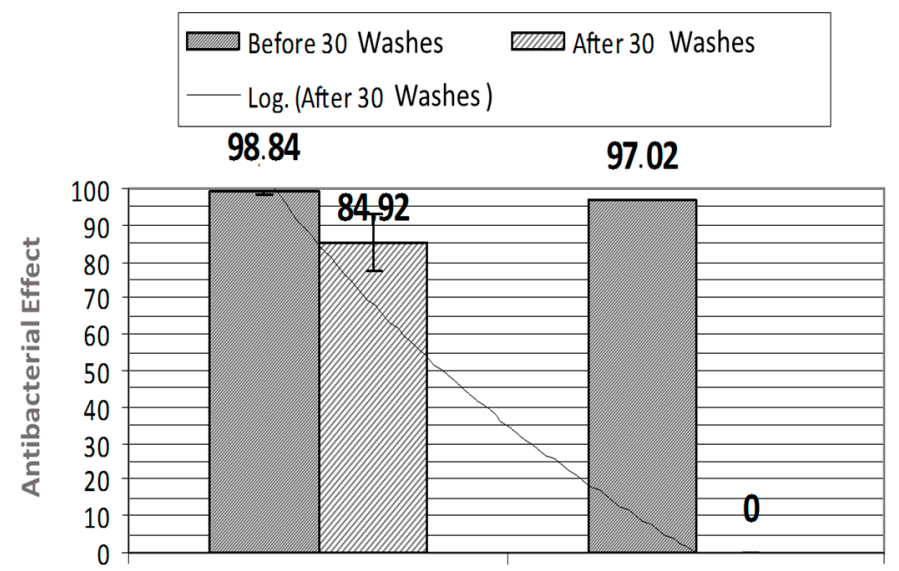

17

18

d)

Textile Samples

Figure 11. Comparison of (a) I2 (cotton, $\mathrm{Ag}, 5 \times 10^{16} \mathrm{ion} / \mathrm{cm}^{2}$ ) and I1 (cotton, $\mathrm{Ag}, 5 \times 10^{15} \mathrm{ion} / \mathrm{cm}^{2}$ ), (b) I3 (polyester, $\mathrm{Ag}$, $5 \times 10^{16} \mathrm{ion} / \mathrm{cm}^{2}$ ) and I4 (polyester, $\mathrm{Ag}, 5 \times 10^{15} \mathrm{ion} / \mathrm{cm}^{2}$ ), (c) $\mathrm{I} 5$ (cotton, $\mathrm{TiO}_{2}, 5 \times 10^{16} \mathrm{ion} / \mathrm{cm}^{2}$ ) and $\mathrm{I}_{6}\left(\mathrm{cotton}, \mathrm{TiO}_{2}\right.$, $5 \times 10^{15} \mathrm{ion} / \mathrm{cm}^{2}$ ), and (d) $\mathrm{I} 7$ (polyester, $\mathrm{TiO}_{2}, 5 \times 10^{16} \mathrm{ion} / \mathrm{cm}^{2}$ ) and $\mathrm{I} 8$ (polyester, $\mathrm{TiO}_{2}, 5 \times 10^{15} \mathrm{ion} / \mathrm{cm}^{2}$ ) .
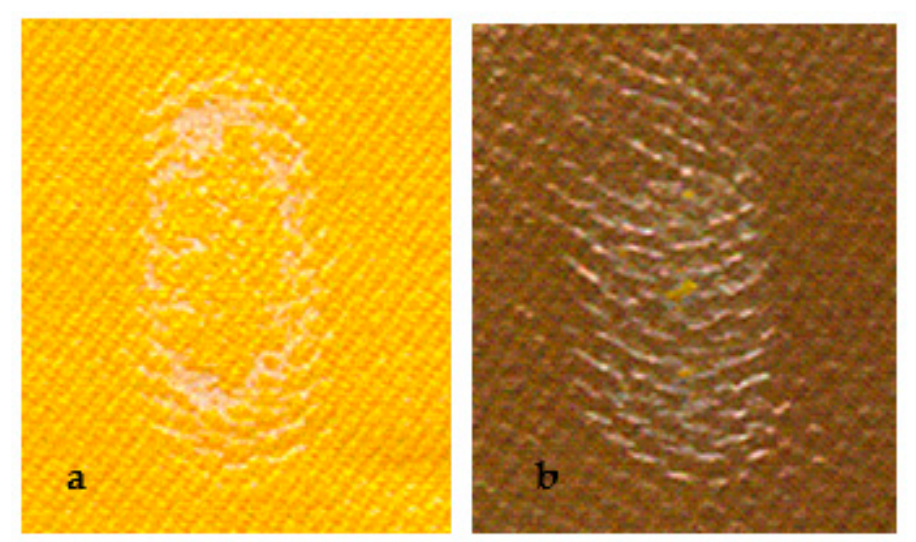

Figure 12. Pictures of (a) untreated and (b) $5 \times 10^{15}$ ion $/ \mathrm{cm}^{2}$ Ti-implanted polyester fabric after the same number of cycles in an abrasive oscillatory cylinder. 


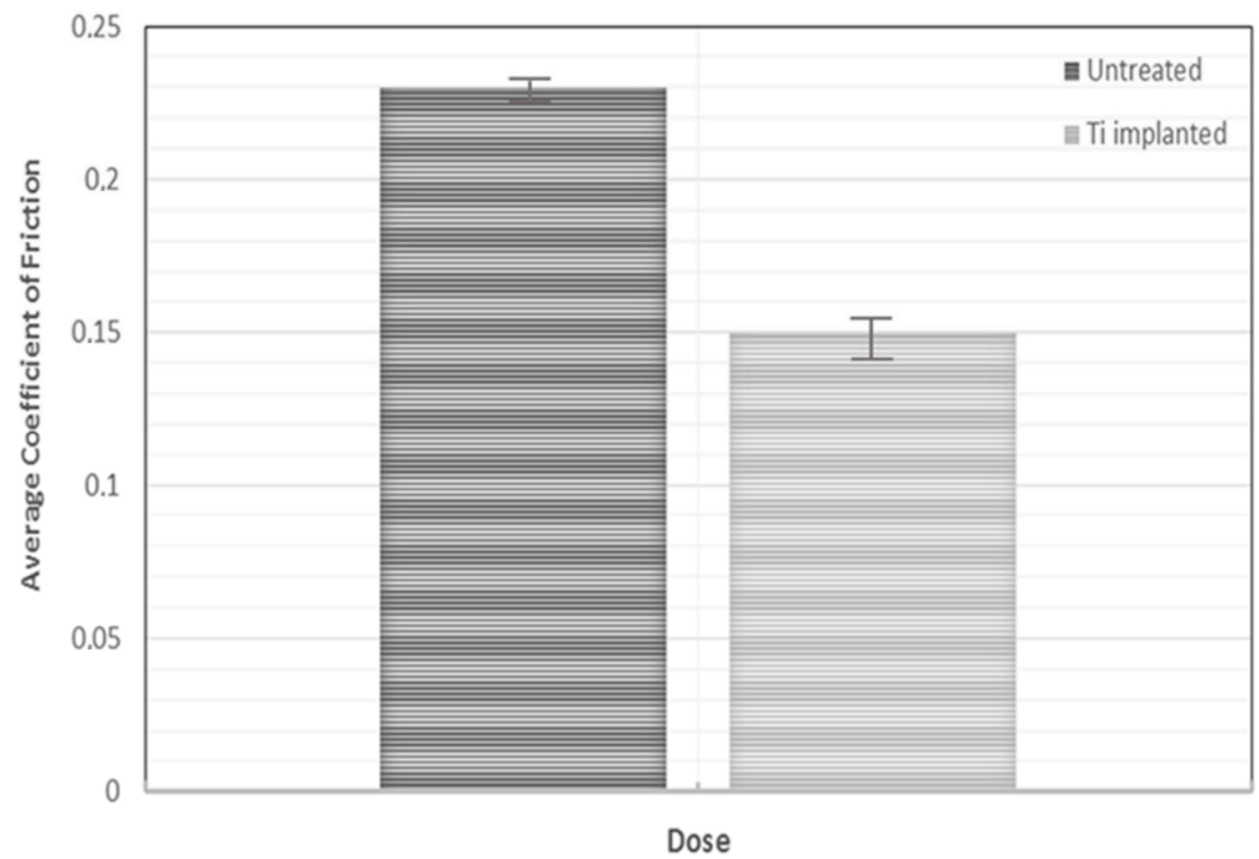

Figure 13. Comparison of the average coefficient of friction values of untreated and $5 \times 10^{15} \mathrm{ion} / \mathrm{cm}^{2}$ Ti-implanted polyester fabrics.

$250 x$
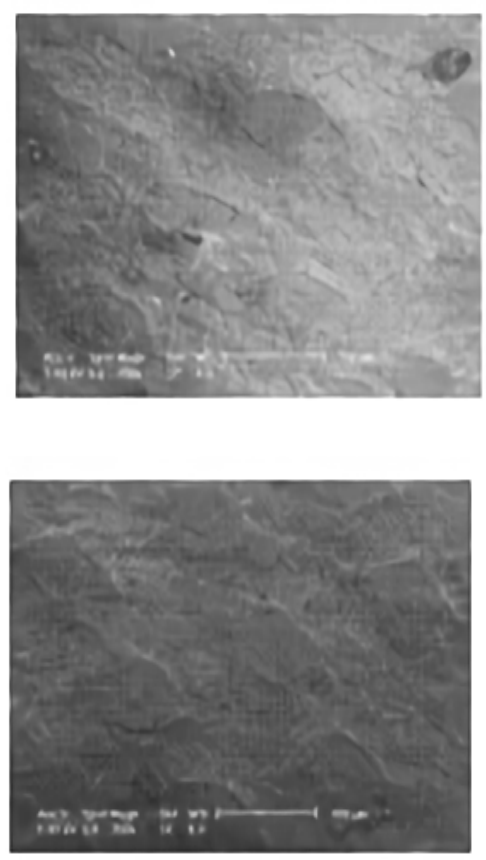

$2500 x$
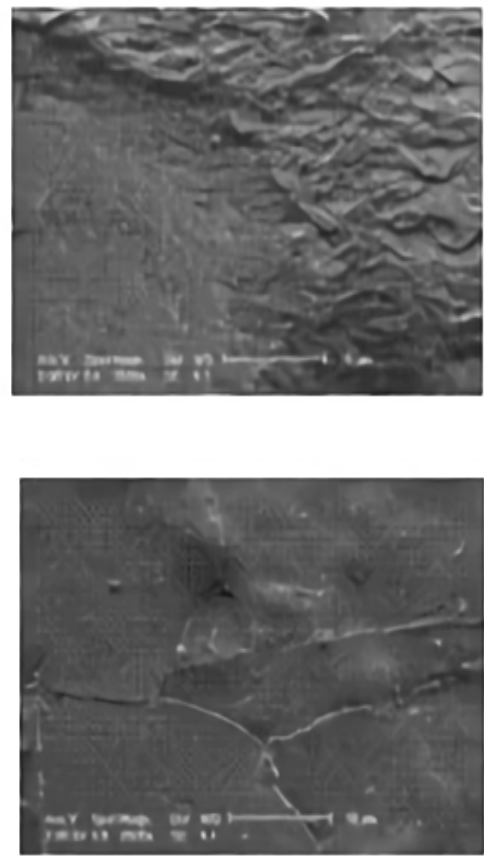

$10000 x$
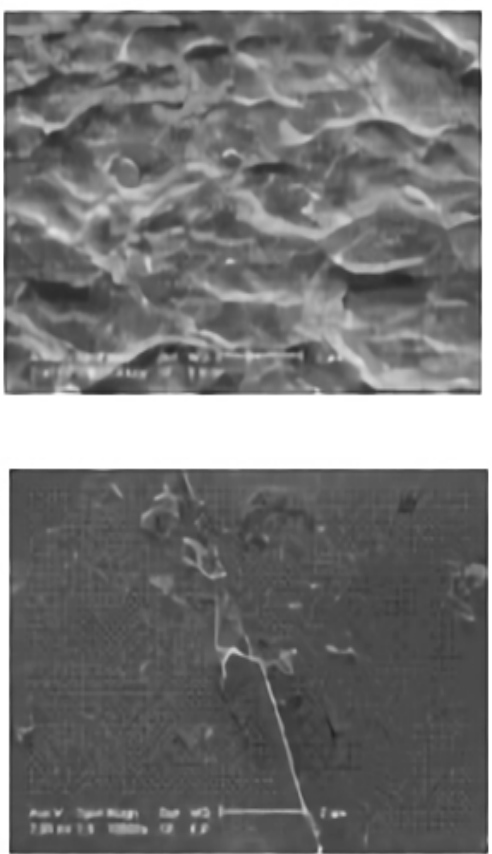

Figure 14. SEM micrographs of untreated and $5 \times 10^{15} \mathrm{ion} / \mathrm{cm}^{2}$ Ti-implanted samples.

\subsection{UV Protection Factor of $5 \times 10^{15} \mathrm{Ion} / \mathrm{cm}^{2} \mathrm{Ag}$ Ion-Implanted Polyester Fabric}

After UV protection factor (UPF) tests were carried out on $5 \times 10^{15} \mathrm{ion} / \mathrm{cm}^{2} \mathrm{Ti}$ and $5 \times 10^{15}$ ion $/ \mathrm{cm}^{2} \mathrm{Ag}$ ion-implanted samples, the results were compared with an untreated sample. As a result, it is understood that while Ti-implanted samples increased the UPF by more than two times, Ag-implanted samples increased UPF by more than six times. Therefore, Ag-implanted samples can be categorized as samples with a very good protection factor. It will be a strong suggestion to claim that if the ion dose is increased to 
$1 \times 10^{17}$ ion $/ \mathrm{cm}^{2}$, the UPF would be higher. The UPF classification is shown in Table 4, and the results are presented in Figure 15.

Table 4. UV protection factor classification.

\begin{tabular}{cc}
\hline UV Protection Factor & Protection Standard \\
\hline $15-24$ & Good Protection \\
$25-39$ & Very Good Protection \\
$40-50,50+$ & Excellent Protection \\
\hline
\end{tabular}

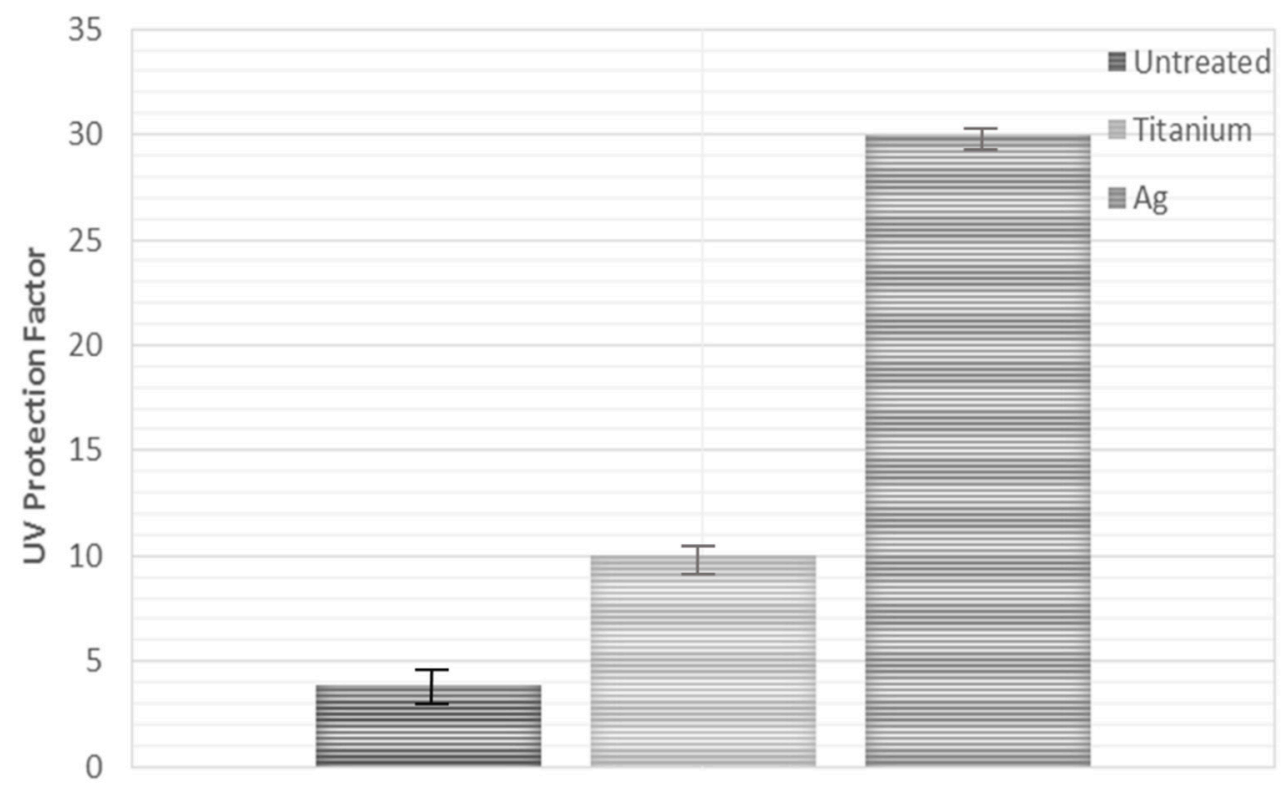

ION TYPE

Figure 15. Comparison of UV protection factors of untreated, $5 \times 10^{15} \mathrm{ion} / \mathrm{cm}^{2}$ Ti ion-implanted, and $5 \times 10^{15} \mathrm{ion} / \mathrm{cm}^{2} \mathrm{Ag}$ ion-implanted samples.

\section{Conclusions}

In this research, first, a group of polyester- and cotton-based medical textiles were treated with $\mathrm{Ag}$ and $\mathrm{TiO}_{2}$ ion beams in different doses. Then, another group of polyesterand cotton-based medical textiles were treated with nanoparticles contained in liquid solutions. The antibacterial efficiencies of the improved fabrics were compared before and after 30 washes in order to evaluate their resistance against laundering and which technique enables antibacterial agents to bind to fabric surfaces strongly.

At the end of the experiment, it was understood that while nanoparticles are superior for cotton fabric, ion implantation is more successful with polyester fabrics. Overall, it can be said that both techniques are equal in creating antibacterial effects. However, some researchers claim that there may be a toxicity problem caused by nanoparticles. In case of a discovery of serious toxicity problems with nanoparticles that are used in nanotextiles, ion implantation technology, which has no known toxicity problem, is ready to serve the textile industry.

In addition to antibacterial efficiency, it is proven that $\mathrm{Ag}$ and $\mathrm{Ti}+\mathrm{O}$ implantation have serious effects on friction resistance and UV protection. Therefore, in conclusion, if the ion doses and textile features are optimized or other ion implantation techniques are utilized, it will not be just a dream to fabricate a "smart textile" with infinite antibacterial efficiency, a very low friction resistance that enables textiles to endure for generations against corrosion, and very high UV protection capability that reduces cancer risk effectively. Additionally, water permeability, wrinkle recovery, and radiation absorbance features of textile surfaces 
may be enhanced when $\mathrm{Ag}$ and $\mathrm{Ti}+\mathrm{O}$ ions are implanted. Also medical textiles with infinite antibacterial ability will have capability to reduce the global medical waste amount significantly [34]. This is another research idea that need to be focused. All these ideas may be considered in future studies.

Funding: This research received no external funding.

Institutional Review Board Statement: Not applicable.

Informed Consent Statement: Not applicable.

Data Availability Statement: The data presented in this study are available within the article.

Acknowledgments: I would like to thank Mustafa Ahmet ÖZTARHAN for all the effort, supervision, equipment, and SEM images he has provided for this research. Unfortunately, during the preparations of the manuscript, he passed away. May he rest in peace forever.

Conflicts of Interest: The authors declare no conflict of interest.

\section{References}

1. Mejía, M.L.; Zapata, J.; Cuesta, D.P.; Ortiz, I.C.; Botero, L.E.; Galeano, B.J.; Hoyos, L.M. Properties of antibacterial nano textile for use in hospital environments. Revis. Ing. Biomed. 2017, 11, 13-19. [CrossRef]

2. Morais, D.S.; Guedes, R.M. Antimicrobial approaches for textiles: From research to market. Materials 2016, 9, 498. [CrossRef] [PubMed]

3. Gokarneshan, N.; Chandrasekar, P.T.; Suvitha, L. Advances in nanotextile finishes-An approach towards sustainability. In Textiles and Clothing Sustainability; Muthu, S., Ed.; Springer: Singapore, 2017; pp. 1-56.

4. Islam, S.; Shabbir, M.; Mohammad, F. Insights into the functional finishing of textile materials using nanotechnology. In Textiles and Clothing Sustainability; Muthu, S., Ed.; Springer: Singapore, 2017; pp. 97-115.

5. Krce, L.; Šprung, M.; Maravić, A.; Umek, P.; Salamon, K.; Krstulović, N.; Aviani, I. Bacteria exposed to silver nanoparticles synthesized by laser ablation in water: Modelling E. coli growth and inactivation. Materials 2020, 13, 653. [CrossRef] [PubMed]

6. Li, J.; He, J.; Huang, Y. Role of alginate in antibacterial finishing of textiles. Int. J. Biol. Macromol. 2017, 94, 466-473. [CrossRef] [PubMed]

7. Turakhia, B.; Divakara, M.B.; Santosh, M.S.; Shah, S. Green synthesis of copper oxide nanoparticles: A promising approach in the development of antibacterial textiles. J. Coat. Technol. Res. 2020, 17, 531-540. [CrossRef]

8. Zemljič, L.F.; Peršin, Z.; Šauperl, O.; Rudolf, A.; Kostić, M. Medical textiles based on viscose rayon fabrics coated with chitosanencapsulated iodine: Antibacterial and antioxidant properties. Text. Res. J. 2018, 88, 2519-2531.

9. Fouda, A.; Saad, E.L.; Salem, S.S.; Shaheen, T.I. In-vitro cytotoxicity, antibacterial, and UV protection properties of the biosynthesized zinc oxide nanoparticles for medical textile applications. Microb. Pathog. 2018, 125, 252-261. [CrossRef]

10. Ouadil, B.; Amadine, O.; Essamlali, Y.; Cherkaoui, O.; Zahouily, M. A new route for the preparation of hydrophobic and antibacterial textiles fabrics using Ag-loaded graphene nanocomposite. Colloids Surf. 2019, 579, 123713. [CrossRef]

11. Edgetech. Ion Implantation. Available online: https://www.edge-techind.com/category/Ion-implantation-44-1.html (accessed on 17 January 2021).

12. IBAD Lab. IBAD Laboratory. Available online: https:// fyzika.fs.cvut.cz/laboratorIBADEN.php (accessed on 17 January 2021).

13. Öktem, T.; Özdogan, E.; Namligöz, S.E.; Öztarhan, A.; Tek, Z.; Tarakçioglu, I.; Karaaslan, A. Investigating the applicability of metal ion implantation technique (MEVVA) to textile surfaces. Text. Res. J. 2006, 76, 32-40.

14. Öktem, T.; Tarakcıŏ̆lu, I.; Özdoğan, E.; Öztarhan, A.; Namlıgöz, E.S.; Karaaslan, A.; Tek, Z. Modification of friction and wear properties of PET membrane fabrics by MEVVA ion implantation. Mat. Chem. Phys. 2008, 108, 208-213.

15. Nikolaev, A.G.; Yushkov, G.Y.; Oks, E.M.; Oztarhan, A.; Akpek, A.; Hames-Kocabas, E.; Urkac, E.S.; Brown, I.G. Modification of anti-bacterial surface properties of textile polymers by vacuum arc ion source implantation. Appl. Surf. Sci. 2014, 310, 51-55. [CrossRef]

16. Anna, K.; Mateusz, S.; Eva., K. Similarities and differences between silver ions and silver in nanoforms as antibacterial agents. Int. J. Mol. Sci. 2018, 19, 444.

17. Alavi, M.; Rai, M. Recent advances in antibacterial applications of metal nanoparticles (MNPs) and metal nanocomposites (MNCs) against multidrug-resistant (MDR) bacteria. Expert Rev. Anti-Infect. 2019, 17, 419-428. [CrossRef]

18. Ward, L.P.; Purushotham, K.P.; Manory, R.R. MEVVA ion implantation of TiCN coatings; structural and tribological properties. Nucl. Instrum. Methods Phys. Res. Sect. 2019, 449, 40-48. [CrossRef]

19. Wang, C.C.; Chen, C.C. Physical properties of crosslinked cellulose catalyzed with nano titanium dioxide. J. Appl. Polym. Sci. 2005, 97, 2450-2456. [CrossRef]

20. Vaishya, R.; Agarwal, A.K.; Tiwari, M.; Vaish, A.; Vijay, V.; Nigam, Y. Medical textiles in orthopedics: An overview. J. Clin. Orthop. Trauma 2018, 9, S26-S33. [CrossRef] [PubMed] 
21. Ward, L.P.; Purushotham, K.P.; Manory, R.R. Nuclear instruments and methods in physics research B studies on the surface modification of TiN coatings using MEVVA ion implantation with selected metallic species. Nucl. Insturm. Methods Phys. Res. 2016, 368, 37-44. [CrossRef]

22. Dastjerdi, R.; Montazer, M. A review on the application of inorganic nano-structured materials in the modification of textiles: Focus on anti-microbial properties. Coll. Surf. 2010, 79, 5-18. [CrossRef]

23. Yuranova, T.; Rincon, A.G.; Pulgarin, C.; Laub, D.; Xantopoulos, N.; Mathieu, H.J.; Kiwi, J. Performance and characterization of Ag-cotton and $\mathrm{Ag} / \mathrm{TiO}_{2}$ loaded textiles during the abatement of E. coli. J. Photochem. Photobiol. 2006, 181, 363-369. [CrossRef]

24. AATCC Test Method 100-1999, Assessment of Antibacterial Finishes on Textile Materials; AATCC: Research Triangle Park, NC, USA, 1999.

25. AATCC 124-2006, Test Method Appearance of Fabrics After Repeated Home Laundering; AATCC: Research Triangle Park, NC, USA, 2006.

26. ASTM D4157-13, Standard Test Method for Abrasion Resistance of Textile Fabrics (Oscillatory Cylinder Method); ASTM International: West Conshohocken, PA, USA, 2013.

27. Öztarhan, A.; Akpek, A.; Oks, E.; Nikolaev, A. Modifying medical textiles with antibacterial and friction resistance abilities by an alternative nanotextile technology called ion implantation technique. In Proceedings of the 2010 15th National Biomedical Engineering Meeting, Antalya, Turkey, 21-24 April 2010; pp. 1-4.

28. Menter, J.M.; Hatch, K.L. Clothing as solar radiation protection. Curr. Probl. Derm. 2003, 31, 50-63.

29. AATCC 183:2014, Test Method for Transmittance or Blocking of Erythemally Weighted Ultraviolet Radiation through Fabrics; AATCC: Research Triangle Park, NC, USA, 2014.

30. Öztarhan, A.; Akpek, A.; Oks, E.; Nikolaev, A. Modifying textiles with antibacterial effect, friction resistance, UV protection and electrostatic charge decay abilities by an alternative nanotextile technology called MEVVA ion implantation technique. In Proceedings of the VIth Nanoscience and Nanotechnology Conference (NANOTR), Izmir, Turkey, 15-18 June 2010.

31. Nikolaev, A.G.; Savkin, K.P.; Yushkov, G.Y.; Oks, E.M.; Oztarhan, A.; Akpek, A.; Cireli, I. Modification of the textile materials by vacuum arc ion source implantation. In Proceedings of the 10th International Conference on Modification of Materials with Particle Beams and Plasma Flows (10th CMM), Tomsk, Rusya, 19-24 September 2010; pp. 401-404.

32. Buras, E.M., Jr.; Goldthwait, C.F.; Kraemer, R.M. Measurement and theory of absorbency of cotton fabrics. Text. Res. J. 1950, 20, 239-248. [CrossRef]

33. Nayfeh, M.H. (Ed.) Delivery of nanoparticles on surfaces. In Fundamentals and Applications of Nano Silicon in Plasmonics and Fullerines: Current and Future Trends; Elsevier: Amsterdam, The Netherlands, 2018; pp. 341-362.

34. Koçak, O.; Kurtuldu, H.; Akpek, A.; Koçoğlu, A.; Eroğul, O. A medical waste management model for public private partnership hospitals. In Proceedings of the 2016 Medical Technologies National Congress (TIPTEKNO), Antalya, Turkey, 27-29 October 2016; pp. $1-4$. 